\title{
Short-term Load Forecasting of Electric Power System Based On Meteorological Factors
}

\author{
Jing Liu \\ Department of Electrical Engineering, North China Electric Power University (Baoding), Baoding, \\ 071000, China
}

email: 2065478882@qq.com

\begin{abstract}
Keywords: Short-term load forecasting; Meteorological factor; Wavelet analysis; Gray relational degree; Dynamic neural network
\end{abstract}

\begin{abstract}
In this paper, it analyzes the characteristics of the changes of meteorological factors and short-term load. Besides, it studies the relationship between meteorological factors (temperature, humidity, rainfall) and short-term load forecasting, so as to select the important meteorological factors, after which, it forecasts the short-term load according to the similar meteorological factors. Next, by means of wavelet transform and Fourier analysis, the variation characteristics of load and meteorological factors are obtained. And then, the influence factors are defined to measure the effect of various meteorological factors on load by using regression coefficient. Finally, through the gray relational degree, the correlation degree is selected in the date of 0.98 or more. Then the load data of these dates are used to train the neural network repeatedly and repeatedly to get more accurate predictive value.
\end{abstract}

\section{Introduction}

To provide users with high quality and stable electric energy is the main task of the power system, and scientific prediction is the basis and guarantee of correct decision. Load forecasting is a powerful tool for the enterprise to understand the user's power demand, law and change trend, and to achieve the optimal allocation of power system resources.

For short term load forecasting, the change law of power network load should be fully studied, and the related factors of load variation. The key meteorological factors are temperature change, followed by humidity, wind and other factors. So we need to make statistical analysis of the historical meteorological conditions. According to the former, the relationship between meteorological factors and load is established to scientifically and reasonably evaluate the link between the two, and the high accuracy prediction model can be used to improve the accuracy of prediction.

In the literature [2],it detailed analysis of the main meteorological factors on the impact of the load, and real-time weather information is referenced to the artificial neural network model, which improves the accuracy of short-term load forecasting. In the literature [3], it established the correlation model between the main meteorological factors and the power system, and the load and established a correction model based on the change trend between the meteorological factors. In the literature [4],the effect of temperature is studied on the load change of continuous high temperature day, and it puts forward the model of the character and load amendment under the effect of summer temperature accumulation. However, the model established in this paper only takes into account the forecast days before the meteorological factors, which may reduce the prediction accuracy.

\section{Historical Data Analysis}

Based on the short term load forecasting of electric power system based on large data mining, it is 
first to master the law of the change of historical load data, and then establish the corresponding data model to predict the future load. Firstly, the correlation between meteorological factors and short-term load is analyzed. Then, by means of wavelet analysis, the four components of the load at any time are obtained: base load component, weather sensitive load component, abnormal or special event load component and random load component.

Correlation analysis between meteorological factors and load. In this paper, the relative calculation of partial least squares regression is realized by MATLAB programming, and the regression coefficients of independent variables to the dependent variables are obtained. The daily maximum load, daily minimum load, daily average load and meteorological factors were analyzed, and the regression coefficient was shown in Table 1.

Table.1 Table of regression coefficient

\begin{tabular}{ccccccc}
\hline & $\begin{array}{c}\text { Maximum } \\
\text { temperature }\end{array}$ & $\begin{array}{c}\text { Minimum } \\
\text { temperature }\end{array}$ & $\begin{array}{c}\text { Average } \\
\text { temperature }\end{array}$ & $\begin{array}{c}\text { Relative } \\
\text { humidity }\end{array}$ & Rainfall & Constant \\
\hline $\begin{array}{c}\text { Daily } \\
\text { maximum load }\end{array}$ & 75.1719 & 54.9405 & 81.5000 & -12.5095 & 4.6294 & 5431.9000 \\
$\begin{array}{c}\text { Daily minimum } \\
\text { load }\end{array}$ & 55.9865 & 40.2191 & 60.6325 & -10.6293 & 3.3181 & 2223.6000 \\
$\begin{array}{c}\text { Daily average } \\
\text { load }\end{array}$ & 68.3248 & 48.8769 & 79.9730 & -13.3322 & 4.0115 & 4085.0000 \\
\hline
\end{tabular}

Next, we define an influence factor to describe the effects of various meteorological factors on daily maximum load, daily minimum load and daily average load.

$$
\boldsymbol{I}_{i j}=\frac{C_{i j}}{\sum_{i=1}^{\mathrm{m}}\left|C_{i j}\right|}
$$

$I_{i j}$ is the influence of the $i_{t h}$ weather factors on the daily maximum load, daily minimum load or daily average load. $C_{i j}$ is the first $i_{t h}$ weather factor on the daily maximum load, the daily minimum load factor. The influencing factors are summarized in table 2 :

Table .2 Influence coefficient table

\begin{tabular}{cccccc}
\hline & $\begin{array}{c}\text { Maximum } \\
\text { temperature }\end{array}$ & $\begin{array}{c}\text { Minimum } \\
\text { temperature }\end{array}$ & $\begin{array}{c}\text { Average } \\
\text { temperature }\end{array}$ & $\begin{array}{c}\text { Relative } \\
\text { humidity }\end{array}$ & Rainfall \\
\hline $\begin{array}{c}\text { Daily } \\
\text { maximum load }\end{array}$ & 0.3690 & 0.2697 & 0.4000 & -0.0614 & 0.0227 \\
$\begin{array}{c}\text { Daily minimum } \\
\text { load }\end{array}$ & 0.3744 & 0.2690 & 0.4055 & -0.0711 & 0.0222 \\
$\begin{array}{c}\text { Daily average } \\
\text { load }\end{array}$ & 0.3637 & 0.2602 & 0.4257 & -0.0710 & 0.0214 \\
\hline
\end{tabular}

As can be seen from the table 2, the highest temperature, the lowest temperature and the average temperature in a variety of weather factors on the daily maximum load, daily minimum load and daily average load of the greatest impact. If the weather factor is selected to establish a simplified short-term load forecasting, the maximum temperature, minimum temperature and average temperature can be given priority.

\section{Characteristic Analysis Of Load And Meteorological Factors}

The wavelet transform is used to decompose the continuous sequence into three scales, which is 
divided into 4 components, each of which is a continuous curve. Because the load of the power system has obvious periodic characteristics (such as day, week, month, quarter, year periodicity), this paper studies their periodic variation characteristics by Fourier analysis.
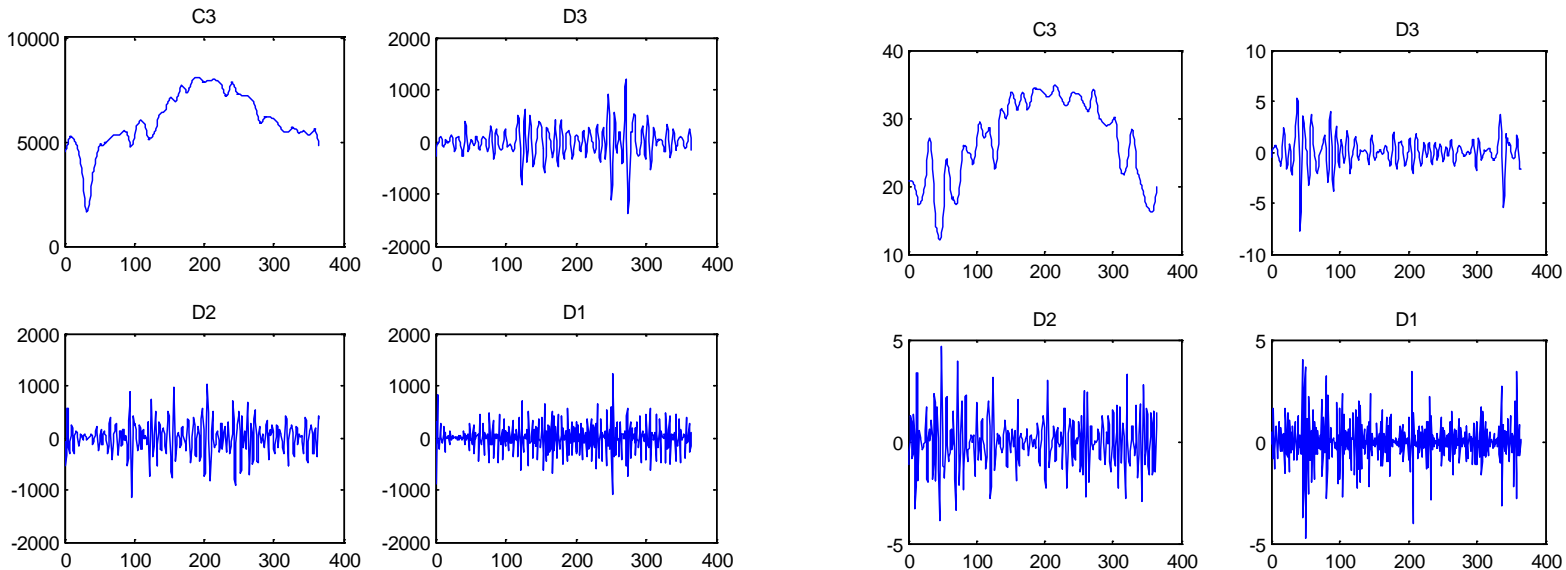

(a)

(b)
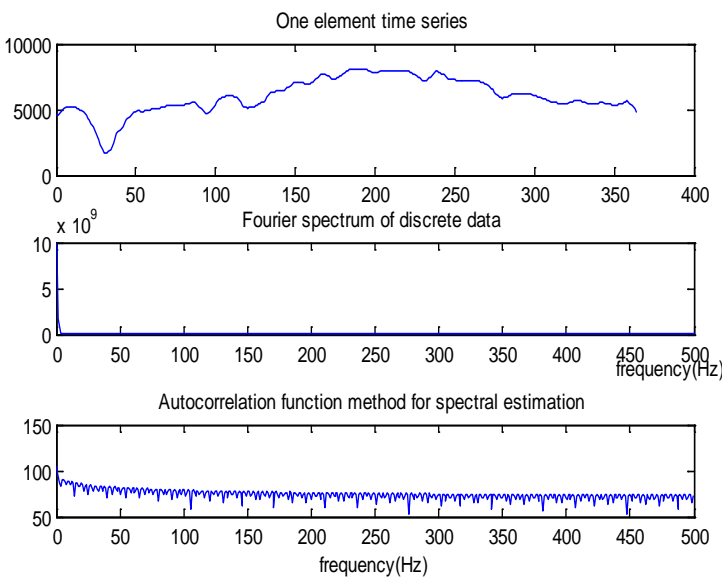

(c)
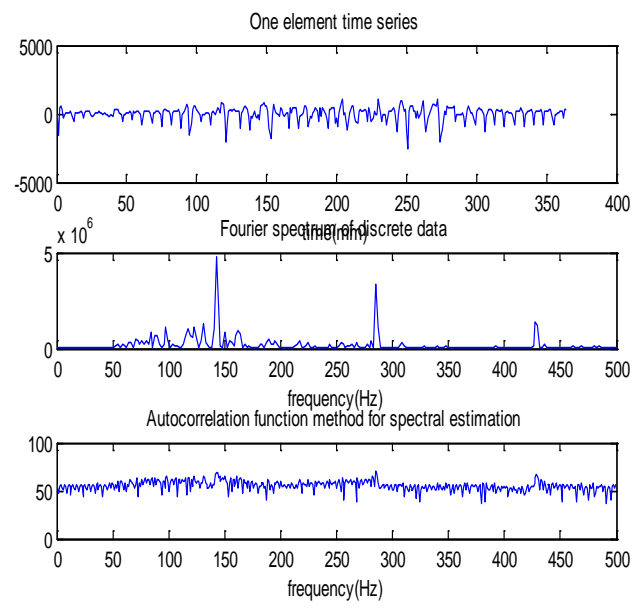

(d)
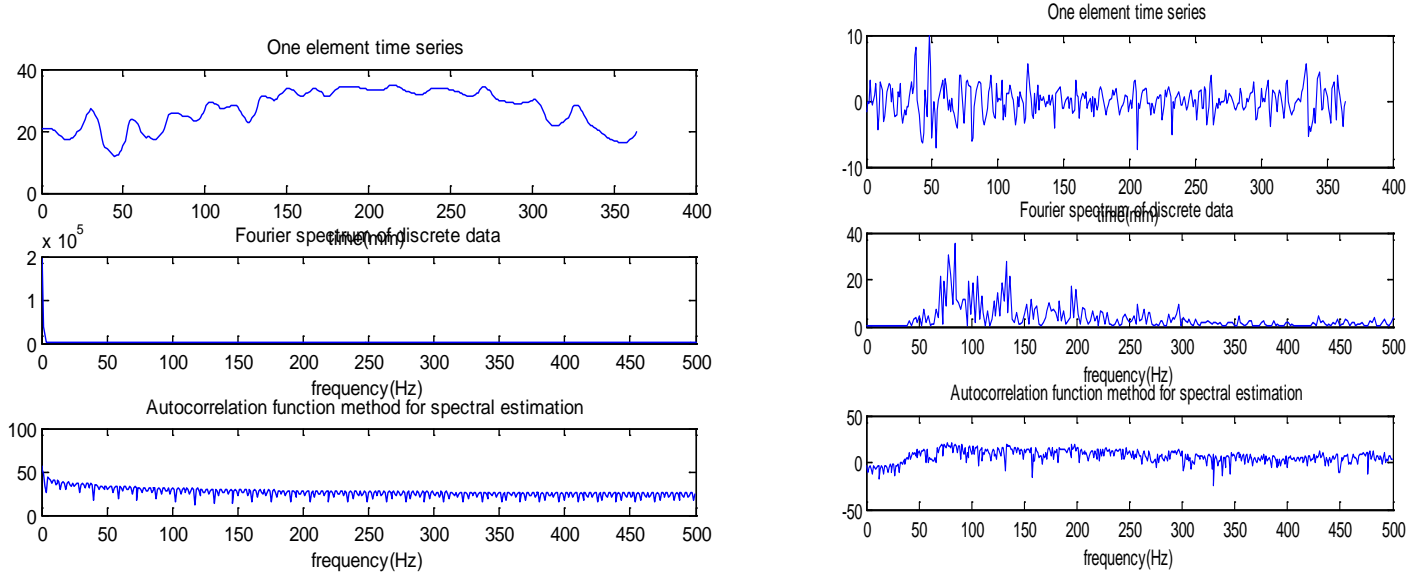

(e)

(f)

Fig.1 (a) Wavelet decomposition of load $\quad$ (b) Wavelet decomposition of maximum temperature

(c)Fourier analysis of the main components of the load (d)Fourier analysis of the secondary components of the load (e)Fourier analysis of the main components of the maximum temperature (f)Fourier analysis of the secondary component of the highest temperature 
Combined with wavelet analysis and Fourier analysis, it can be seen that the main components of the load and temperature are stable, but not periodic, and the secondary component has obvious periodicity.

\section{Short Term Electric Load Forecasting}

The meteorological similarity factor and the time similarity factor are used to predict the trend of the two places in the future. In the historical load data, if the temperature is similar to the two date, the load curve also has the similar variation characteristic. So it can be used to modify the predicted daily load curve. For historical data, the more close to the forecast date of the meteorological factors, the more similar the load curve.

Gray relational grade analysis. Similarity factor, the maximum, minimum and average temperature and rainfall and humidity five indicators to determine, the five value as a feature vector, and then through the gray correlation analysis method to calculate forecast, and history, between meteorological similarity factor. First of all, to establish the forecast date and historical date of the meteorological factors, the Japanese character vector $T_{0}=\left[t_{0}(1), t_{0}(2), \ldots, t_{0}(\mathrm{~m})\right]$ and $T_{i}=\left[t_{\mathrm{i}}(1), t_{\mathrm{i}}(2), \ldots, t_{\mathrm{i}}(\mathrm{m})\right]\left(t_{0}, t_{1}, t_{\mathrm{m}}\right.$ are $M$ meteorological factors $)$. The gray correlation coefficient between the first I and the current forecast is obtained by the gray relational grade analysis:

$$
\xi_{i}(k)=\frac{\min _{i} \min _{k} \Delta_{i}(k)+\rho \max _{i} \max _{k} \Delta_{i}(k)}{\Delta_{i}(k)+\max \max \Delta_{i}(k)}
$$

Among them: $\Delta_{i}(k)=\left|t_{0}(k)-t_{i}(k)\right|$ is the absolute value of the difference between the predicted date and the historical date of $K$ meteorological factors. $P$ is a between 0 and 1 between the weight coefficient to be 0.5 .

Meteorological similarity factor . The meteorological similarity factor between the forecast date and the historical date is $r_{i}$. The meteorological similarity factor $r_{i}$ is between 0 and 1 . The greater the change of $r_{i}$, the greater the gray correlation degree between the two days, and the higher the degree of similarity. Specific calculation formula is as follows :

$$
r_{i}=\frac{1}{m} \sum_{k=1}^{m} \xi_{i}(k)
$$

Here is the flow chart of forecasting model:

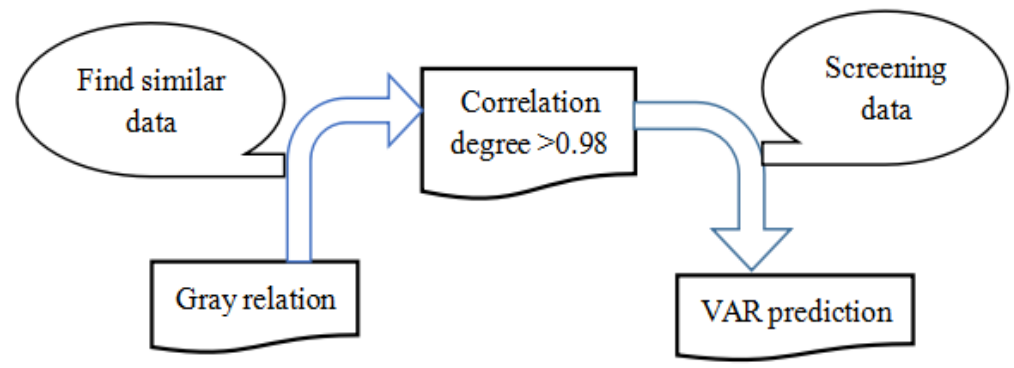

Fig .2 Flow chart of forecasting model

Solving model. The following is a day of 96 sampling points and other historical data of the gray correlation. And filter the data objects with the degree of correlation in 0.98 or more. 


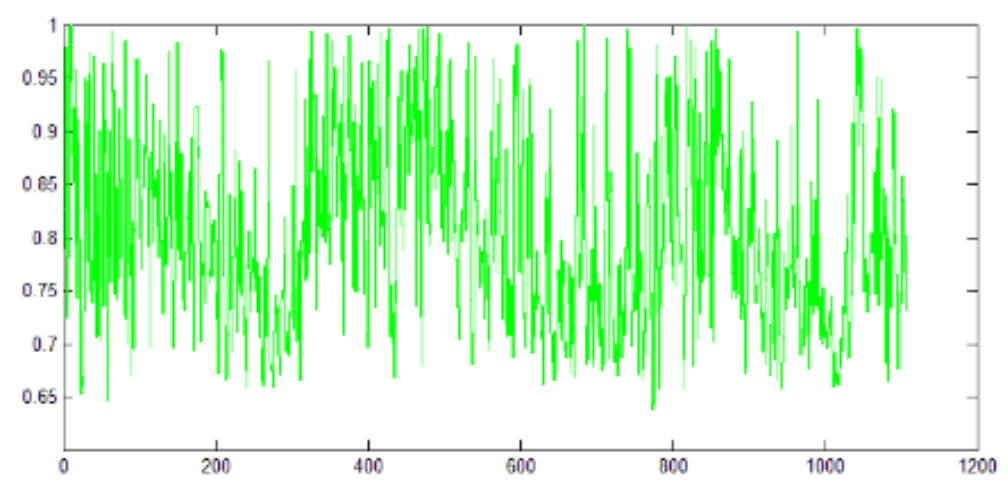

Fig.3 Gray correlation degree of meteorological factors

Dynamic neural network time series forecasting method is dependent on the front of the output and the current input, and has a feedback effect. Dynamic neural network is easy to deal with the irregular data, and it can satisfy the nonlinear auto regressive model in dynamic neural network time series forecasting. After repeated training and testing, the model is shown in Figure 4.

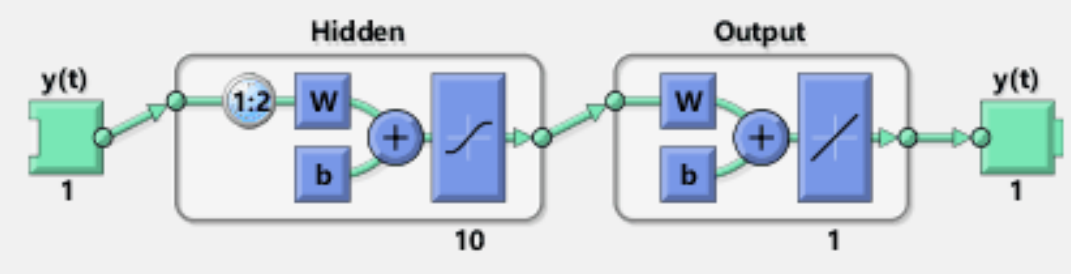

Fig.4 Dynamic neural network prediction model

Through the repeated training and verification of the neural network in the historical data of more than 0.98, the result of dynamic neural network time series can be obtained in January 11, 2015.

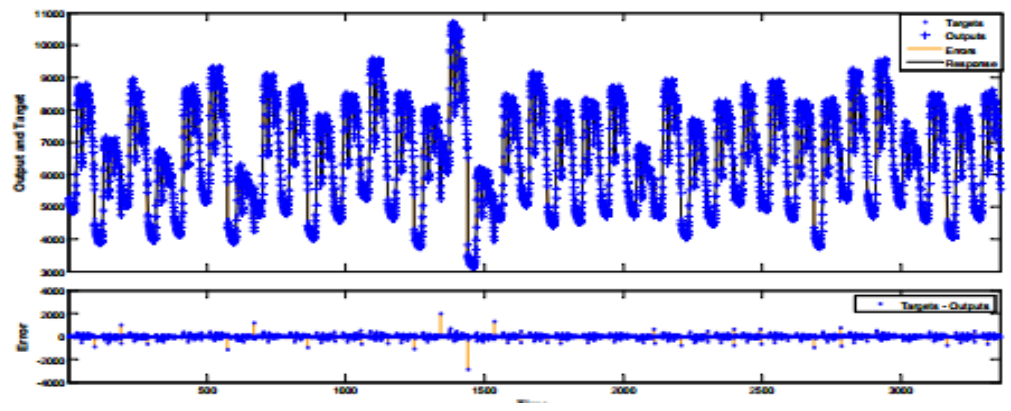

Fig.5 Real time prediction map

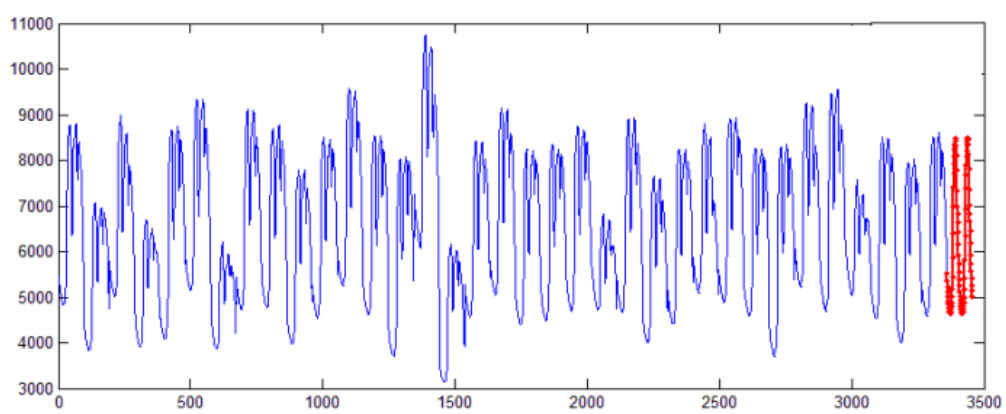

Fig.6 Forecast result

As can be seen from the figure 5 , the error is very small, only a few large. However, regardless of meteorological factors, although the error is not too large, but compared to the meter and meteorological factors, much bigger, especially in the second half of the real-time forecast. From figure 6 and can be seen, predicted on January 11, load the data before compared with very similar 
fluctuations, strong regularity, also shows that the load and meteorological factors affecting the prediction accuracy is improved.

\section{Summary}

This paper focuses on the relationship between power system load and meteorological factors, using wavelet analysis to decompose the power system load and weather factors, and extract their details. Due to the obvious daily, weekly, monthly, quarterly and annual cycle characteristics of the power load, the Fourier analysis is used to study the periodic characteristics of each feature. Finally, by using the gray correlation analysis, the similar meteorological factors were selected, and the short-term load forecasting based on VAR neural network has achieved good results.

\section{References}

[1] Information on http://www.chinaqking.com/yc/2014/444029.html

[2] P. Wang, N. Tai, B. Bo, H. Zhai, J. Ye, L. Li, J. Zhu, painted beams, According to the meteorological factors of the short-term load forecasting correction method. Automation of electric power systems, 2008, vol. 13, pp. 92-96.

[3] C. Li, P. Yang, W. Liu, D. Li, et al, In short term load forecasting considering the summer temperature cumulative effect, Automation of electric power systems, 2009, vol. 09, pp. 96-99.

[4] H. Li, Short term load forecasting of electric power system considering real time meteorological factors, North China Electric Power University, 2015

[5] J. Jiang, Short term power load forecasting based on wavelet denoising and artificial neural network, Guangxi University, 2013

[6] W. Han, Z. Ning, Dynamic neural network prediction method of time series of, microcomputer development, 2004, vol. 09, pp. 40-41. 